\title{
Influence of Thermal and Morphological Behaviour on Biomass Waste Materials during Pyrolysis
}

\author{
Swapan Suman ${ }^{1 *}$, Santosh Kumar Rai ${ }^{1}$, Anand Mohan Yadav ${ }^{2}$, Awani Bhushan ${ }^{3}$, Nomendra Tomar ${ }^{1}$, Rajneesh Kumar \\ Singh $^{4}$, Ansar Ali SK ${ }^{1}$, Anuj Kumar Mishra ${ }^{1}$ \\ ${ }^{1}$ Department of Mechanical Engineering, Meerut Institute of Engineering and Technology, Meerut-250005, Uttar Pradesh, India \\ ${ }^{2}$ Department of Chemical Engineering, Meerut Institute of Engineering and Technology, Meerut-250005, Uttar Pradesh, India \\ ${ }^{3}$ School of Mechanical and Building Sciences, VIT Chennai, Tamil Nadu - 600127, India \\ ${ }^{4}$ Department of Mechanical Engineering, NIET, NIMS University Jaipur, Rajasthan, 303121, India
}

\begin{abstract}
Aim of this study to investigate the thermal and morphological behaviour of different types of biomass feedstock. For investigation of thermal behaviour we used thermo-gravimetric (TG) analysis and derivative thermo-gravimetric (DTG) analysis. The biomass feedstocks were conceded out under vigorous conditions using nitrogen gas at specific heating rates to gradient the temperature from $25^{\circ} \mathrm{C}$ to $1000^{\circ} \mathrm{C}$. The derivative thermo-gravimetric (DTG) results show that thermal decomposition on these feedstocks. First-order reaction model were used to determine the kinetics parameters for the pyrolysis of biomass wastes. This study used Field Emission Scanning Electron Microscopy (FE-SEM) to observe surface morphology properties of the different biomass wastes. The FE-SEM images showed that clearly retained the fibrous structures in the biomass wastes and were rich in macro-pores.
\end{abstract}

\section{Introduction}

The raising the energy demand secured with the necessity to minimise the GHG radiation and the threat of reducing fossils fuel reserves has carried into emphasis on the alternative renewable source of energy. Among the various renewable energy sources, biomass has the potential to be used as alternative source of energy with zero emissions.

Developed and developing countries have already encompassed the exceptional idea of usage of biomass [1] and are quiet depending on accessibility of natural resources including coal gas and oil.

Biomass can be transformed into the various forms of energy using different treatments [2]. The knowledge on thermal properties of the different biomass gives better support to comprehend on thermochemical processes at industrial scale [3]. Other investigators have estimated these properties including motile parameters on biomass under ideal conditions [2, 4-7]. Utilization of biomass wastes in energy production is very important because the depletion of fossil fuels. It would also be a very effective way for the removal of bio-waste, which occupies humongous volumes when disposed to a landfill [8] and direct burning of these wastes emits GHG emissions into the environment.

Pyrolysis is one of the thermo-chemical processes that are conducted at high temperatures in the absence of air (oxygen). Throughout the pyrolysis process, biomass is converted into solid, liquid and gaseous products based on heating rates, time and temperature [9]. Hence we can say that energy generated from biomass has a high capacity to bridge the global energy shortage gap caused by the depletion of fossil fuel resources while keeping environmental sustainability. 'Thermo-gravimetric' (TG) and 'derivative thermogravimetric' (DTG) analysis is the most operational method to compare the thermal kinetics and trials during the thermochemical process such as combustion and pyrolysis [10-14]. It determines the weight loss percentage of sample as a function between time and temperature. The decomposition reactions can takes place in the testing sample start by TGA at given temperature [15-18].

It is important to comprehend that how the morphological characteristics are influenced by different biomass feedstocks with different pyrolysis conditions. Field Emission Scanning Electron Microscopy (FE-SEM) provides a shortest way to detect the surface structure and mineral distribution of biomass and their corresponding char [19-21].

This study demonstrates the comparative effects of heating temperature $\left(400,600,800\right.$ and $\left.1000^{\circ} \mathrm{C}\right)$ on the physiognomies of bio-chars Thermo-gravimetric and morphological analysis were used for this study. 


\section{MATERIALS AND METHODOLOGY}

\subsection{Biomass materials and Preparation of Biochar}

Figures Biomass samples mainly used for this study are Tea Wastes (TW), Coconut Shell (CS) and Eucalyptus Shell (ES). The parameters like feedstock type and heating profile (i.e. pyrolysis temperature) have been frequently recognised as important variables for determining the composition and characteristics of produced bio-char [22-25]. Besides, the significance of pyrolysis time during biochar production is less conclusive due to a limited number of studies varying these conditions. Therefore detailed investigations would aid in reaching a definitive conclusion on the importance and preferred value for these variables. The heating temperature range studied throughout the experimental work covered a range from $400^{\circ} \mathrm{C}$ to $1000^{\circ} \mathrm{C}$. This temperature choice covered the main regions of biomass degradation as well as the respective upper and lower limits of temperatures associated with slow pyrolysis at slow heating rate (15$25^{\circ} \mathrm{C} / \mathrm{min}$ ) [26]. A low heating rate was selected to provide longer heating time in an attempt to provide tolerable time for sufficient heat transfer and heat penetration into the biomass particles. Based on realistic times seen in industrial sized units to generate fast conversion of feedstock to biochar, the residence times chosen were therefore 60 minutes.

\subsection{Methodology}

\subsubsection{Proximate and ultimate analyses and higher heating value $(H H V)$}

"Proximate analysis" was employed on selected and prepared materials for the estimation of physiochemical properties with ensuing standards “(ASTM E871-82, E1755-01, and E872-82)" [27]. And the proximate analysis for obtained biochar from studied samples was evaluated according to "ASTM D1762-84" standard method [28].

"ASTM E777, E778 and E775" standard method was ensued for "ultimate analysis" [29] to calculate the elemental components of the selected samples and their corresponding biochar using "CHNS analyser" (Vario EL III). In the ultimate analysis we determine the Carbon, Hydrogen, Nitrogen and Sulphur in weight percentage.

Higher Heating Value (HHV) of all samples were estimated by "bomb calorimeter" (Model: AC-350 LECO) according to "ASTM D4809" standard [30].

\subsubsection{Thermo-gravimetric analysis (TGA) and differential thermal gravimetric analysis (DTG)}

The experimental work was carried out using a NETZSCH SAT 449F3 thermo-gravimetry analyser. The TGA/DTA facilitated the attainment of weight loss, and mass range data as a function of heating rate, time and temperature. The complete explanation of the experiment is provided by Suman and Gautam [31]. The process starts at room temperature to $105^{\circ} \mathrm{C}$.

5-15 mg of sample was taken and heated up to a final temperature of $700^{\circ} \mathrm{C}$ at an increment rate of $36 / 10^{\circ} \mathrm{C} / \mathrm{min}$ with $20 \mathrm{ml} / \mathrm{min}$ flow rate of nitrogen. It gives an assortment of temperature in which maximum thermal degradation of samples takes place.

\subsubsection{FE-SEM (Field Emission Scanning Electron Microscope)}

FE-SEM is an excellent technique for analysing the morphological behaviour of solid particles. The samples were coated in conductive tapes and examined using an SUPRA'55 MonoCL4 field emission scanning electron microscope (FE-SEM). The magnifications of the FE-SEM images were selected as $100 \mathrm{X}$ to $15000 \mathrm{X}$.

\section{RESULTS AND DISCUSSION}

\subsection{Proximate, ultimate analyses and heating values of studied biomass samples}

The proximate, ultimate analyses and heating values of the studied biomass samples are summarized in Table 1(a) and (b). As per the various literature [32], the parametric values of samples vary in the range: ash (5.06-10.04\%), VM (66.54-73.68\%), FC (14.71$15.19 \%), \mathrm{C}(39.17-45.55 \%), \mathrm{O}(48.52-55.65 \%), \mathrm{H}$ (4.73-5.41\%), $\mathrm{N}(0.31-0.67 \%)$, and $\mathrm{S}(0.14-0.19 \%)$. Their ash depends on the feedstock types with their terrestrial region

Table 1(a)

Proximate analysis (dry basis), Ultimate analysis and higher heating value of studied biomass samples

\begin{tabular}{l|l|l|l|l}
\hline Samples & M \% & Ash \% & VM \% & FC \% \\
\hline Tea Waste & $8.20 \pm 0$. & $5.66 \pm 0$. & $71.43 \pm 0$. & $14.71 \pm 0$. \\
(TW) & 27 & 16 & 33 & 11 \\
\hline Coconut & $6.07 \pm 0$. & $5.06 \pm 0$. & $73.68 \pm 0$. & $15.19 \pm 0$. \\
Shell (CS) & 15 & 22 & 36 & 09 \\
\hline Eucalyptus & $8.59 \pm 0$. & $10.04 \pm$ & $66.54 \pm 0$. & $14.83 \pm 0$. \\
Shell (ES) & 44 & 0.43 & 60 & 32 \\
\hline
\end{tabular}

Table 1(b)

Ultimate analysis and higher heating value of studied biomass samples

\begin{tabular}{l|l|l|l|l|l|l}
\hline Samples & $\begin{array}{l}\mathbf{C} \\
\mathbf{\%}\end{array}$ & $\begin{array}{l}\mathbf{H} \\
\mathbf{\%}\end{array}$ & $\begin{array}{l}\mathbf{N} \\
\mathbf{\%}\end{array}$ & $\begin{array}{l}\mathbf{S} \\
\mathbf{\%}\end{array}$ & $\begin{array}{l}\mathbf{O} \\
\mathbf{\%}\end{array}$ & $\begin{array}{l}\mathbf{G C V} \\
(\mathbf{M J} / \mathbf{k g})\end{array}$ \\
\hline $\begin{array}{l}\text { Tea Waste } \\
\text { (TW) }\end{array}$ & 42.19 & 5.01 & 0.67 & 0.19 & 51.94 & 15.09 \\
\hline $\begin{array}{l}\text { Coconut } \\
\text { Shell (CS) }\end{array}$ & 45.55 & 5.41 & 0.37 & 0.15 & 48.52 & 18.10 \\
\hline $\begin{array}{l}\text { Eucalyptus } \\
\text { Shell } \\
\text { (ES) }\end{array}$ & 39.17 & 4.73 & 0.31 & 0.14 & 55.65 & 15.24 \\
\hline
\end{tabular}

The HHV of selected biomass vary in the range of $15.09-18.10 \mathrm{MJ} / \mathrm{Kg}$. These values are also within the range of literature value [33] and that is comparable with primary and other renewable energy source. 
Heating value directly affected by ash, its high or less weight percentage depends on the calorific value which shows their heating energy.

From above result and data, it can be decided that less ash containing samples makes it more desirable as a 'fuel' [34-35].

In particular, the fast growing crops mostly have higher content of ash $\mathrm{Cl}, \mathrm{K}, \mathrm{Mg}, \mathrm{S}, \mathrm{Na}$, and $\mathrm{Si}$ [36-37]. The higher HHV of coconut shell is because of lower content of ash i.e. an incombustible component and higher amount of combustible components such as volatile matter, fixed carbon, carbon and hydrogen than in other biomass materials.

\subsection{Compositional analysis of studied biomass samples}

The composition of biomass can be characterized by some major components like cellulose, hemicellulose, lignin and extractives. The concentration of each component depending on types of feedstocks, but there is also a lot of variation within a single feedstock. This variation depends on their terrestrial and geological area. Table 2 compiles the data on the composition of different biomass samples. Determining the composition of studied biomass is detailed and complex undertaking when all of the constituents are individually measured. These compositional components were calculated by analytical method [38].

Table 2

Compositional analysis of studied biomass Samples

\begin{tabular}{|c|l|l|l|l|}
\hline Samples & $\begin{array}{l}\text { Extractiv } \\
\text { es }\end{array}$ & $\begin{array}{l}\text { Hemicell } \\
\text { ulose }(\%)\end{array}$ & $\begin{array}{l}\text { Lignin } \\
(\mathbf{\% )}\end{array}$ & $\begin{array}{l}\text { Cellulose } \\
(\mathbf{\%})\end{array}$ \\
\hline TW & 11.39 & 28.21 & 21.00 & 27.96 \\
\hline CS & 9.50 & 20.50 & 26.80 & 42.17 \\
\hline ES & 22.31 & 21.50 & 24.00 & 11.96 \\
\hline
\end{tabular}

As a fuel, heating value is plays an important role for any biomass material, is pretentious by the amount of extractives (a combustible organic constituents). The gross calorific values or heating values of the extractive-free were found to be lower than those of the extracted part indicates a likely positive influence of extractives towards the increase of heating values. High extractive content of agricultural biomass part makes it predictable as fuel [32]. The heating value narrates to the oxygen contents required for complete combustion. Typically, $30-60 \mathrm{wt} \%$ of the dry matter in biomass is oxygen, from which lignin has higher degree of oxidation than cellulose and hemicellulose [39]. After analysing the extractive content and GCV of biomass, it was found that lignin found to contribute to GCV followed by cellulose and hemicellulose. That means, there is no direct relation between GCV, cellulose and hemicellulose of the agricultural biomass samples, but lignin content directly affects the gross calorific value of the agricultural biomass [32]. Lignin has contains higher energy (about 30-40\%) than cellulose and hemicellulose. GCV of all agricultural biomass increases with increase in lignin contents [40], because of its greater amount of oxidation.

\subsection{TG/DTG analysis of the studied biomass samples}

TG/DTG tests were carried out to conclude the imperative evidence such as stage change with temperatures and weight losses occurs during combustion process for studied agricultural biomass samples. DTG entails of the derivative of the TG curve, giving mainly the same information, but in a much more visual and clear way. They both are presented in Figures 1 (a)-(c). TG analysis exemplifies the rate of change of mass with respect to temperature at specified heating and its possibility towards pyrolytic process [41]. This is worth mentioning that the biomass basically consists of hemicelluloses, cellulose and lignin, where the content of the individual component varies depending on the type of the biomass. According to the TGA curves, between $65 \%$ and $95 \%$ of the samples were decomposed at temperature below $700^{\circ} \mathrm{C}$, wherein the weight loss mostly occurred at the temperature between $150^{\circ} \mathrm{C}$ and $450^{\circ} \mathrm{C}$. The behaviour reflects in less mass loss in the sample due to the higher mineral content, which acts as a barrier that prevents the diffusion of heat, and hence the less release of the volatile component during the carbonising process [42].

The DTG curves for the different agricultural biomass samples are shown in Figures 1 (a)-(c). Generally, two distinct peaks can be seen for the temperature action of biomass in a passive atmosphere [43], where the first peak is dispensed to the thermal breakdown of hemicelluloses and another one is for the cellulose and then lignin breakdown, which covers a longer range.

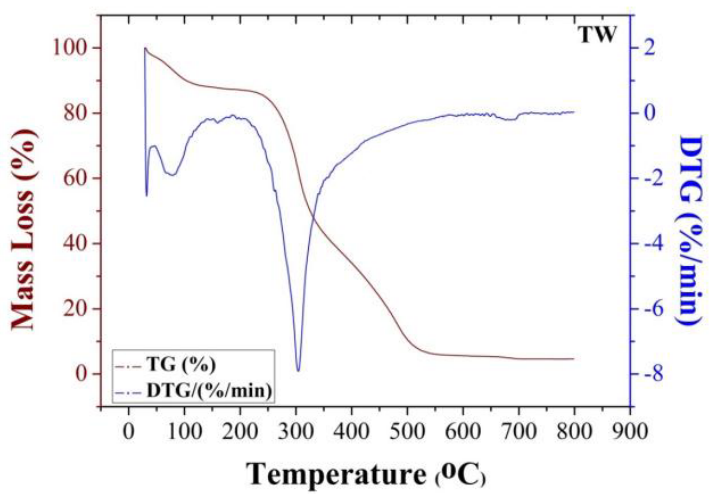

Fig. 1 (a). TG-DTG analysis of TW 


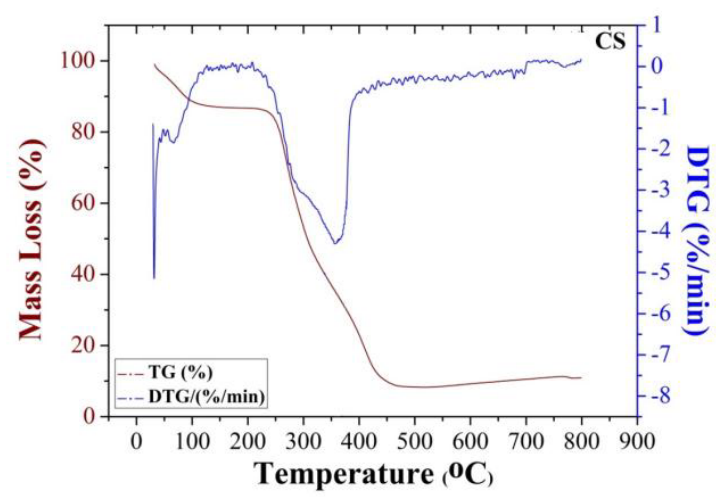

Fig. 1(b). TG-DTG analysis of CS

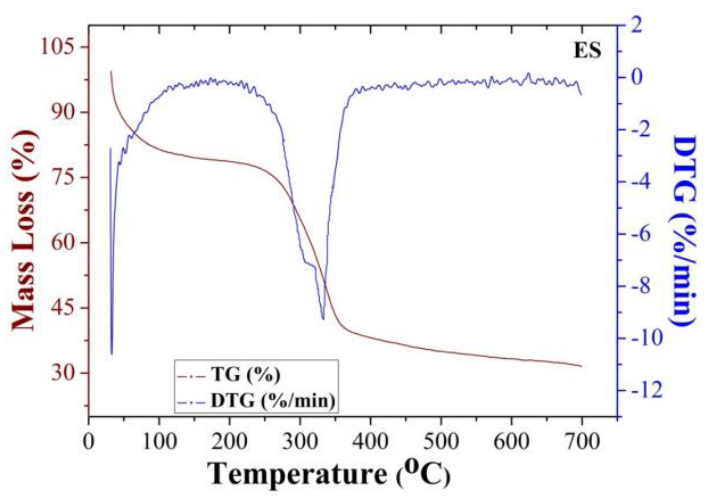

Fig. 1(c). TG-DTG analysis of ES

From the DTG (first derivative) profile for the rate of weight loss, the behaviour of all the different samples shows three distinct peaks, indicating that the degradation can be explained by dividing the curve into three stages, as shown in Figure 1 (a)-(c), the initial mass loss starts at $70^{\circ} \mathrm{C}$, its mass loss occurs due to the presence of moisture in the sample. In the second stage from $290-305^{\circ} \mathrm{C}$ the maximum weight loss achieved at $300^{\circ} \mathrm{C}$ is attributable to the hemicelluloses deprivation. The third stage appeared from $335-395^{\circ} \mathrm{C}$ with maximum breakdown rate at $365^{\circ} \mathrm{C}$. Compared with cellulose and hemicellulose components, lignin was the most difficult one to crumble even at higher temperature. The highest mass losses in the shortest residence time are indicative short combustion time, which is depicted from figures. Those biomass samples have longer combustion time for its mass loss is interesting for fuel.

\subsection{FE-SEM image analysis of studied biomass samples}

FE-SEM images of all the biomass samples were analyse at magnifications ranging from $50 \mathrm{X}$ to $15000 \mathrm{X}$ which are shown in Figures 2 (a)-(c). Photographic examination of these images demonstrates the transformations in microstructure between the studied samples. FE-SEM images were examined from different point sections of the samples presented that internal parts of these passages are also packed and initially raw forerunners are not porous. The studied biochar samples have typical lingo-cellulosic structure and are made of solid cells in the form of openings on the surface [44]. The morphological structure of the TW, CS and ES showed uniform short fibrous and coarser structure with masses of loose spongy lingocellulosic structures [45].

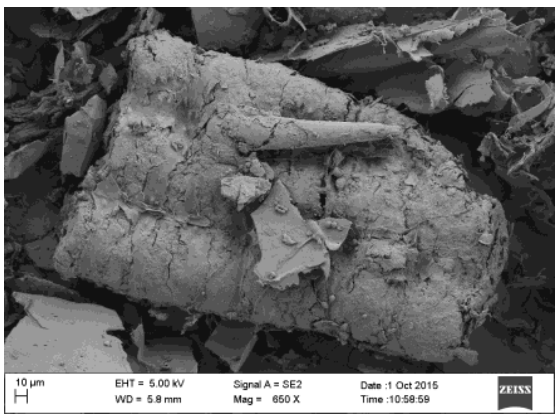

Fig. 2(a). FE-SEM image analysis of TW

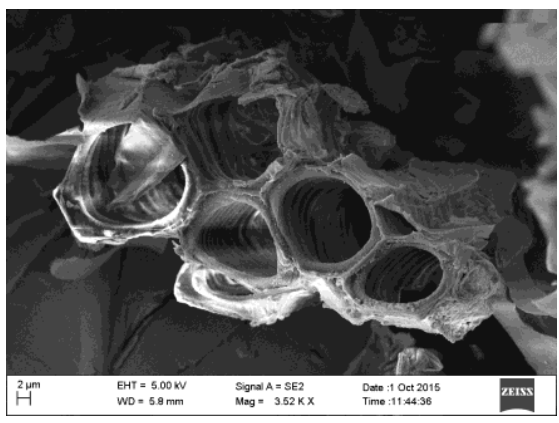

Fig. 2(b). FE-SEM image analysis of CS

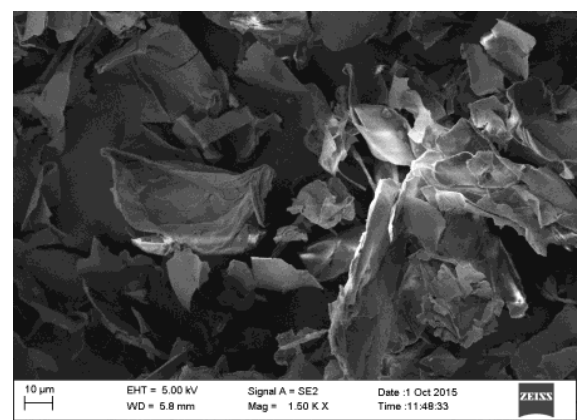

Fig. 2(c). FE-SEM image analysis of ES

Some uneven long and fibrous fragments are observed on the surface of tea waste. Among the all studied samples, CS showed more integral and stable arrangement as of its shell strong nature. On the other hand, TW and ES biomass had a more porous and crumbled arrangement. These biomass samples have flat and long fibres that are mostly composed of tracheid cells and hence give good penetrability.

The fibres in CS samples, which consist of true fibres and hardwood tracheids, are shorter and smaller. Their cracks and voids inside were less open and the surface of the fibre wall sustained the adjacent veracity among fibres for making the xylem tissue [45].

In coconut shell image like spongy structure with small granulated dense channel structures are shown. 


\subsection{Proximate and ultimate analyses of prepared biochar samples at different temperature}

The proximate and ultimate analyses of the carbonized products of different biomass samples at different temperature are incorporated in Table 3 (a) and (b). As per the literature, the parametric values in case of a variety of studied biochar vary in the range: ash $(3.44-$ $23.49 \%)$, VM (5.42 - 57.76\%), FC (38.66-84.68\%), C (33.26-79.46\%), O (16.91-58.22\%), H (1.10-6.34\%), N $(0.32-2.11 \%)$, and $\mathrm{S}(0.02-0.18 \%)$ [47]. Here the values from proximate and ultimate analysis (Table 3 a $\&$ b) of each of the biochar samples differ from each other and are well within these literature values. Biochar is mainly formed from the thermal breakdown of lignin and extractives of samples; while the VM content is converted into the gas stage and minerals presents in the samples are left as ashes [48].

Table 3 (a)

Proximate analysis (dry basis), and Ultimate analysis of the prepared biochars at different temperatures

\begin{tabular}{|l|c|l|l|l|}
\hline \multirow{3}{*}{$\begin{array}{l}\text { Biomass } \\
\text { Feedstock }\end{array}$} & Temperature & VM\% & Ash\% & FC\% \\
\hline \multirow{4}{*}{ TWC } & 400 & 54.76 & 6.58 & 38.66 \\
\cline { 2 - 5 } & 600 & 14.45 & 21.08 & 64.47 \\
\cline { 2 - 5 } & 800 & 5.46 & 22.81 & 71.73 \\
\hline \multirow{4}{*}{ CSC } & 1000 & 4.44 & 23.49 & 72.07 \\
\cline { 2 - 5 } & 400 & 40.63 & 3.44 & 55.93 \\
\cline { 2 - 5 } & 600 & 21.21 & 5.65 & 73.14 \\
\hline \multirow{3}{*}{ ESC } & 1000 & 13.49 & 6.08 & 79.43 \\
\cline { 2 - 5 } & 400 & 45.45 & 16.81 & 37.74 \\
\cline { 2 - 5 } & 600 & 14.63 & 19.44 & 65.93 \\
\cline { 2 - 5 } & 800 & 6.67 & 21.65 & 71.68 \\
\hline
\end{tabular}

Table 3 (b)

Ultimate analysis of the prepared biochars at different temperatures

\begin{tabular}{|c|c|c|c|c|c|c|}
\hline $\begin{array}{c}\text { Sampl } \\
\text { es }\end{array}$ & $\begin{array}{c}\text { Temper } \\
\text { ature }\end{array}$ & C\% & H\% & N\% & S\% & O\% \\
\hline \multirow{4}{*}{ TWC } & 400 & 49.64 & 4.91 & 2.00 & 0.02 & 43.43 \\
\cline { 2 - 7 } & 600 & 58.45 & 3.54 & 1.97 & 0.10 & 35.94 \\
\cline { 2 - 7 } & 800 & 69.26 & 2.34 & 1.21 & 0.11 & 27.08 \\
\cline { 2 - 7 } & 1000 & 71.82 & 1.73 & 0.45 & 0.15 & 25.85 \\
\hline
\end{tabular}

\begin{tabular}{|c|c|c|c|c|c|c|}
\multirow{4}{*}{ CSC } & 400 & 52.39 & 4.68 & 1.99 & 0.13 & 40.81 \\
\cline { 2 - 7 } & 600 & 69.98 & 3.74 & 1.06 & 0.03 & 25.19 \\
\cline { 2 - 7 } & 800 & 77.45 & 3.54 & 0.97 & 0.03 & 18.01 \\
\cline { 2 - 7 } & 1000 & 79.46 & 3.12 & 0.32 & 0.19 & 16.91 \\
\hline \multirow{4}{*}{ ESC } & 400 & 33.26 & 6.34 & 2.11 & 0.07 & 58.22 \\
\cline { 2 - 7 } & 600 & 59.20 & 4.76 & 1.56 & 0.02 & 34.46 \\
\cline { 2 - 7 } & 800 & 68.98 & 2.74 & 1.06 & 0.12 & 28.10 \\
\cline { 2 - 7 } & 1000 & 71.05 & 1.10 & 0.87 & 0.18 & 26.80 \\
\hline
\end{tabular}

From the Table 3(a), it can be seen that volatile matter content of all the biochars gradually decreases with rise in temperature from 400 to $1000^{\circ} \mathrm{C}$. The related figures for TWC, CSC and ESC are in the range (54.764.44), (40.63 - 9.02), and (45.45 - 5.52) wt.\%, respectively. The high VM of biochars derived from agricultural biomass at comparatively low temperatures is ascribable to the existence of lignin in the biomass material, which can moderately resist pyrolytic breakdown at $360-395^{\circ} \mathrm{C}$, but not at temperatures as high as $1000^{\circ} \mathrm{C}$ [42]. The increase in temperature from 350 to $800^{\circ} \mathrm{C}$ is also associated with speedy loss of volatile matter [49]; because of the formation of aromatic molecules.

The ash content in the corresponding biochars varies as (6.58-23.49), (3.44-6.30) and (16.81-22.36) \%, respectively. The observation of higher contents of ash in the ESC than TWC and CSC are similar to the observations of others [49-50]. Additionally, partial change in the configuration supported by a likely interaction between organic and inorganic constituents [42] may be another reason for the higher ash content of the biochars of tea waste and eucalyptus shell materials. Fixed carbon in TWC, CSC and ESC, all biochar sample increases with increase in temperature, the related range values being (38.66-72.07), (53.93$84.68)$ and (37.74-72.22) wt.\%, respectively. Thus biochars with high ash have the lower values of fixed carbon and vice versa.

Volatile Matter decreases with increase in the pyrolysis temperature, presenting a comparable trend with the yield of biochar, whereas dissimilar trend was seen for the Fixed Carbon. This influence is owed by the increase in pyrolysis heat results in further cracking of the volatile segments into small and low molecular weights of liquid and gases instead of biochar [51]. For now, the desiccation of 'hydroxyl groups' and thermal deprivation of cellulose and lignin influence also occur with the increasing the heating temperature [48]. Mentioned facts and data established that the increase in temperature improved the immovability of biochar for the loss of volatile [52]. It was quite fascinating that the ash content unusually increased with the increase in heating temperature from 400 to $1000^{\circ} \mathrm{C}$. The increase in ash caused from lenient concentration of inorganic components [53]. In some cases when pyrolysis temperature increased from 800 to $1000^{\circ} \mathrm{C}$, some 
inorganic matter might have volatilized (as gas or liquid), thus, reducing the ash content at higher temperature $\left(1000^{\circ} \mathrm{C}\right)$.

\subsection{TG/DTG analysis of prepared biochars at different temperature}

TG data analysis demonstrates the rate of change of mass with respect to heating temperature and its viability to pyrolytic process [42]. The weight loss of derived biochar of different agricultural biomass at different temperatures is shown in Figure 3(a)-(c), respectively. This is worth mentioning that the biomass basically consists of hemicelluloses, cellulose and lignin, where the content of the individual component varies depending on the type of the biomass.

During pyrolysis, the decomposition regions of hemicelluloses and cellulose usually occurs in the range of around $220-315^{\circ} \mathrm{C}$ and $315-400^{\circ} \mathrm{C}$, respectively with the maximum mass losses at 268$355^{\circ} \mathrm{C}$, whereas in case of lignin decomposition takes place in a wide range of $180-900^{\circ} \mathrm{C}$ [54]. According to the TGA curves Figure 3(a)-(c), between $70 \%$ and $90 \%$ of the samples were decomposed at temperature below $700^{\circ} \mathrm{C}$, wherein the weight loss mostly occurred at the temperature between $150^{\circ} \mathrm{C}$ and $450^{\circ} \mathrm{C}$. This is a good indication that these wastes are easily decomposed via thermal processing and would be an excellent feedstock for pyrolysis reactions. In particular, the weight loss of coconut shell and others wastes was 70$90 \%$ and $40-50 \%$ of the total weight, respectively [42]. Thus these feedstocks are realised as potential sources for pyrolysis.

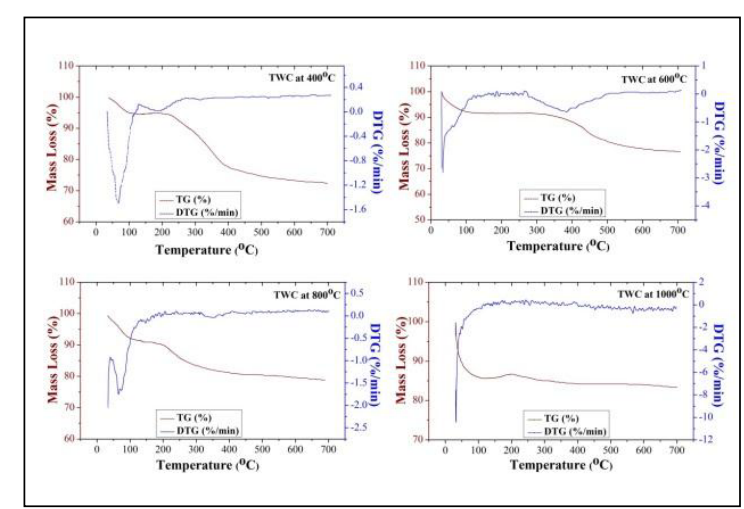

Fig. 3(a). TG/DTG analysis of TWC at different temperature

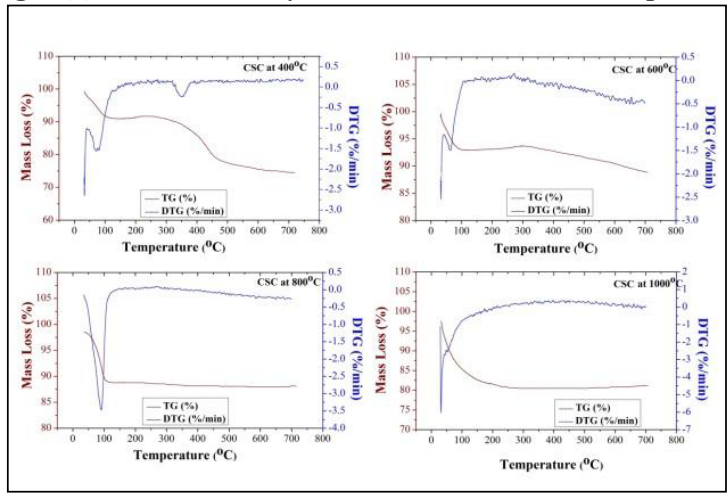

Fig. 3(b). TG/DTG analysis of CSC at different temperature

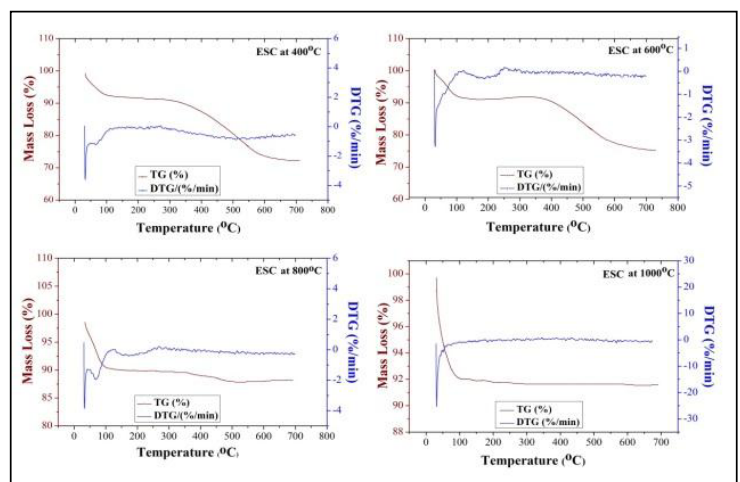

Fig. 3(c). TG/DTG analysis of ESC at different temperature

The DTG curves for biochars are included in Figure 3(a)-(c). From the DTG curve of CSC at $400^{\circ} \mathrm{C}$ it can be seen that the deprivation of cellulose and hemicellulose is complete and the dilapidation of lignin occurred at temperature $350^{\circ} \mathrm{C}$ and beyond. But the DTG profile of the $\mathrm{CSC}$ at $600^{\circ} \mathrm{C}$ and $800^{\circ} \mathrm{C}$ indicates that the decomposition of lignin is complete, and attains steady state at $1000^{\circ} \mathrm{C}$. The DTG profile of CSC at studied heating temperatures is also pertinent to that of the other feedstocks and resultant biochars at studied heating temperatures.

\subsection{FE-SEM image of prepared biochar}

The heating temperature has substantial influence on the pore structure and morphology of biochar [55]. This is because for thermal modification; large amounts of VM drifts from the solid material in a short period of time, that variations the surface, shrinking, and excruciating of the particles [42].

At $800^{\circ} \mathrm{C}$ of temperature, the discharge of volatile matter entirely separates the particles, which initiate a hole-like arrangements and constructions full of passages that might have frolicked the role of stacks during gas release, as can be seen in most of the figures, especially in TWC and ESC. Through this study we found that every sample shows a homogeneous morphological structure. The image of TWC shows amalgam of tiny particles, which is possibly because of cluster, due to the melting of alkali compounds [56].

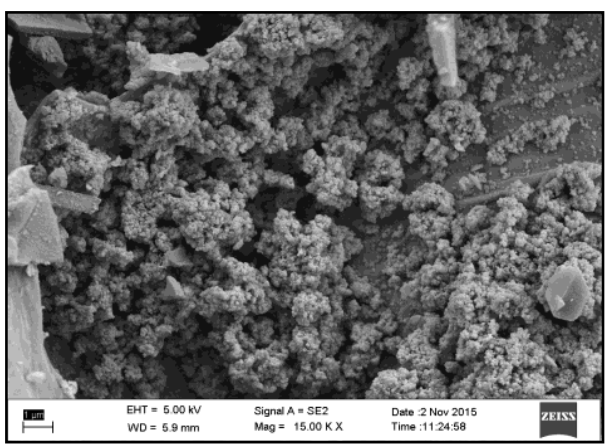

Fig. 4(a). FE-SEM image analysis of TW biochar prepared at $800^{\circ} \mathrm{C}$ temperature 


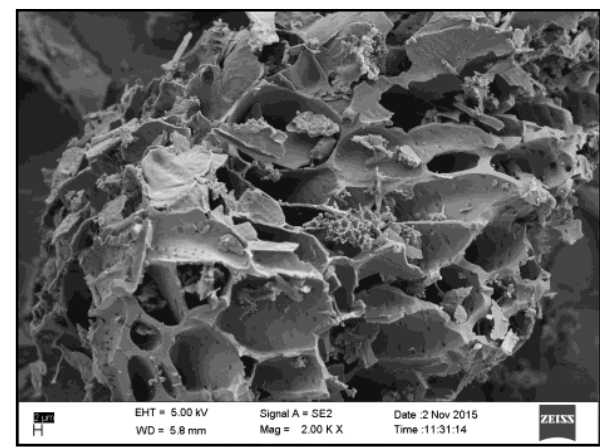

Fig. 4(b). FE-SEM image analysis of CS biochar prepared at $800^{\circ} \mathrm{C}$ temperature

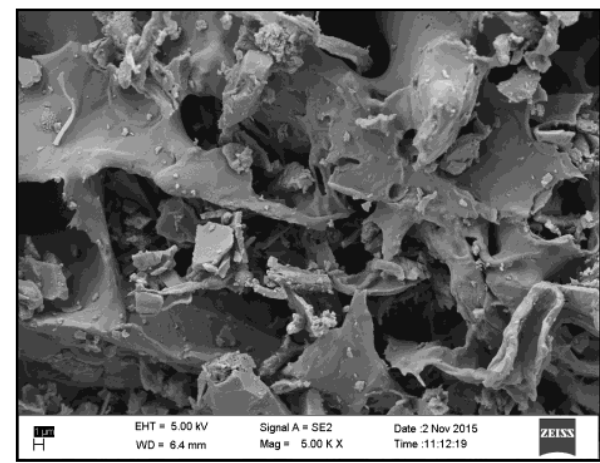

Fig. 4(c). FE-SEM image analysis of ES biochar prepared at $800^{\circ} \mathrm{C}$ temperature

However, there is a large morphological changes occur in the conversion of biomass to biochar. The removal of a substantial amount of volatiles produces pore opening and also it create channel like structure. Thermal breakdown of 'chemical bonds' and the melting of some compounds give more pores.

Hence FE-SEM analysis recommends that the surface area of the biochar can be improved with heating temperature, and this observation is consistent with others' findings [57]. With high pyrolysis temperature, the bio-char surfaces were found to rupture significantly and it had a more split construction instigated by thermal cracking of their raw biomass at $800^{\circ} \mathrm{C}$ temperatures. CSC retained moderately less dissociated surfaces which were due to the fibrous nature of their biomass. However, as it is reported by others [58].

\section{Conclusions}

In this study the pyrolysis of waste like tea waste, coconut shell and eucalyptus shell biomass has been investigated at different temperatures by means of thermo-gravimetric and morphological analysis. This study validates that the type of samples and heating temperature strongly influence the characteristics of the bio-char. Coconut shell has higher content of volatile matter, fixed carbon, $\mathrm{C}, \mathrm{H}$, and higher heating value (HHV) than the others; reverse is true in case of ash, $\mathrm{O}$, $\mathrm{N}$, and $\mathrm{S}$ content. With increase in heating temperature, $\mathrm{VM}$, and $\mathrm{H}$ of all the bio-chars decrease; but ash, FC, C, aromaticity, degree of carbonisation, HHV. Higher the heating temperatures endorse condensation reactions and aromaticity. TG/DTG analysis showed good covenant with experimental data. However, the use of an FE-SEM established a relatively high temperature the tested samples showed signs of softening and enlargement. The results of this study are vital as it provides an insight for future application of biomass as a resource of energy

\section{References}

1. K.B. Ajoku, Modern use of solid biomass in Africa: prospect for utilization of agro-waste resources in Nigeria. In: Rainer Janssen, Dominik Rutz (Eds.), Bioenergy for Sustainable Development in Africa. Springer, Netherland, ISBN 978-94-007-2180-7, pp. 131-146, 2012.

2. X. Zhang, M. Xu, R. Sun, L. Sun, Study on biomass pyrolysis kinetics. Journal of Engineering for Gas Turbines and Power 128, 493-496, 2006.

3. S. Munir, S.S. Daood, W. Nimmo, A.M. Cunliffe, B.M. Gibbs, Thermal analysis and devolatilization kinetics of cotton stalk, sugar cane bagasse and shea meal under nitrogen and air atmospheres, Bioresource Technology 100 (2009) 1413-1418, 2009.

4. A.A. Zabaniotou, E.K. Kantarelis, D.C. Theodoropoulos, Sunflower shell utilization for energetic purposes in an integrated approach of energy crops: laboratory study pyrolysis and kinetics. Bioresource Technology 99, 3174-3181, 2008.

5. M.G. Gronli, G. Varhegyi, C.D. Blasi, Thermogravimetric analysis and devolatilization kinetics of wood. Industrial and Engineering Chemical Research 41, 4201-4208, 2002.

6. O. Senneca, Kinetics of pyrolysis, combustion and gasification of three biomass fuels. Fuel Processing Technology 88, 87-97, 2007.

7. I. Simkovic, K. Csomorova, Thermogravimetric analysis of agricultural residues: oxygen effect and environmental impact. Journal of Applied Polymer Science 100, 1318-1322, 2006.

8. M. Varol, A.T. Atimtay, B. Bay, H. Olgun, Investigation of co-combustion characteristics of low quality lignite coals and biomass with thermogravimetric analysis. Thermochimica Acta, 510 (1-2) 195-201, 2010.

9. J.J. Chew, V. Doshi, Recent advances in biomass pretreatment-Torrefaction fundamentals and technology. Renewable and Sustainable Energy Reviews, 15, 4212-22, 2011.

10. A. Arenillas, F. Rubiera, B. Arias, J.J. Pis, J.M. Faúndez, A.L. Gordon, X.A. García, A TG/DTA study on the effect of coal blending on ignition behaviour. J. Therm. Anal. Calorim. 76, 603-614, 2004.

11. F. Rubiera, A. Arenillas, B. Arias, J.J. Pis, Modification of combustion behaviour and 
NO emissions by coal blending. Fuel Process. Technol. 77-78, 111- 117, 2002.

12. H. Haykırı-Açma, Combustion characteristics of different biomass materials. Energ. Convers. Manage. 44, 155-162, 2003.

13. G. Skodras, P. Grammelis, P. Basinas, Pyrolysis and combustion behaviour of coalMBM blends. Bioresour. Technol. 98, 1-8, 2007.

14. C. Wang, F. Wang, Q. Yang, R. Liang, Thermogravimetric studies of the behavior of wheat straw with added coal during combustion. Biomass Bioenerg. 33, 50-56, 2009.

15. L. Zhou, Y. Wang, Q. Huang, J. Cai,. Thermogravimetric characteristics and kinetic of plastic and biomass blends co-pyrolysis. Fuel Process. Technol. 87, 963-969, 2006.

16. R. Upadhyay, S. K. Rai and G. Dutta, Numerical analysis of density wave instability and heat transfer deterioration in a supercritical water reactor, Journal of Mechanical Science and Technology, 32 (3), 1063-1070, 2018.

17. S.K. Rai, G. Dutta and T. Sheorey, "Stability Analysis of Supercritical Water Natural Circulation Loop with Vertical Heater and Cooler", Proceedings of the 24th National and 2nd International ISHMT-ASTFE Heat and Mass Transfer Conference (IHMTC2017), December 27-30, 2017, BITS Pilani, Hyderabad, India, 2017.

18. S.K. Rai, P. Kumar, and V. Panwar, Numerical analysis of influence of geometry and operating parameters on Ledinegg and dynamic instability on supercritical water natural circulation loop, Nuclear Engineering and Design, 369,110830, 2020.

19. S. Swapan, P. Deepak Singh, G. Shalini, Surface morphology properties of biochars obtained from different biomass waste, Energy Sources, Part A: Recovery, Utilization, and Environmental Effects, 39:10, 1007-1012, 2017.

20. S. K Rai, P. Kumar, V. Panwar, Mathematical and numerical investigation of Ledinegg flow excursion and dynamic instability of natural circulation loop at supercritical condition, Annals of Nuclear Energy, 155, 108129, 2021.

21. S.K. Rai, P. Kumar and V. Panwar, Numerical investigation of steady state characteristics and stability of supercritical water natural circulation loop of a heater and cooler arrangements, Nuclear Engineering and Technology, 53, 3597-3611, 2021.

22. P.T. Williams, S. Besler, The influence of temperature and heating rate on the slow pyrolysis of biomass, Renewable Energy 1481, 6-7, 1996.

23. MJJ Antal, M, Grønli, The Art, Science, and Technology of Charcoal Production, Industrial
\& Engineering Chemistry Research, 42, 1619-1640, 2003.

24. A. Downie, A. Crosky, Munroe, P. Physical properties of biochar. In: Biochar for Environmental Management: Science and Technology. 1st edn (eds Lehmann J, Joseph S), Earthscan, London, 13-29, 2009.

25. D. Angin, Effect of Pyrolysis Temperature and Heating Rate on Biochar Obtained from Pyrolysis of Safflower Seed Press Cake. Bioresource Technology, 128, 593-597, 2013.

26. S. Yaman, Pyrolysis of biomass to produce fuels and chemical feedstock. Energy Conversion and Management, 45 (5), 651671, 2004.

27. A. Demirbas, Effects of temperature and particle size on bio-char yield from pyrolysis of agricultural residues. J. Ana. and App. Pyro., 72, 243-248, 2004a.

28. A. Demirbas, Combustion Characteristics of different biomass fuels. Prog. in En. and Comb. Sci., 30, 219-230, 2004b.

29. HLE. Mena, AAB. Pecora, AL. Beraldo, Slow Pyrolysis of Bamboo biomass: Analysis of Biochar properties. Chemical Engineering Transactions, 37, 115-120, 2014.

30. Z, Movasaghi S, Rehman I. ur Rehman, Fourier Transform Infrared (FTIR) Spectroscopy of Biological Tissues. Applied Spectroscopy Reviews, 43, 134-179, 2008.

31. S. Swapan, G. Shalini, Pyrolysis of coconut husk biomass: Analysis of its biochar properties, Energy Sources, Part A: Recovery, Utilization, and Environmental Effects, 39:8, 761-767, 2017.

32. A. Demirbas, Relationships between heating value and lignin, moisture, ash and extractive contents of biomass fuels. Energy Explor. Exploit., 20, 105-11, 2002a.

33. A. Demirbas, Fuel characteristics of olive husk and walnut, hazelnut, sunflower and almond shells. Energy Sources, 24, 213-9, 2002b.

34. J.O. Titiloye, M.S. Abu Bakar, T.E. Odetoye, Thermochemical cahracteristic of agricultural wastes from West Africa. Industrial Crops and Products, 47, 199-203, 2013.

35. L, Cuiping, CW, Yanyongjie, H. Haitao Chemical elemental characteristics of biomass fuels in China. Biomass Bioenerg., 27, 11930, 2004.

36. LL, Baxter, TR, Miles Jr Miles TR, Jenkins BM, Milne T, Dayton D. The behaviour of inorganic material in biomass-fired power boilers: field and laboratory experiences. Fuel Process Technol., 54, 47-78, 1998.

37. Y, Qian Zuo C, Tan J, J. He, Structural analysis of bio-oils from sub and supercritical water liquefaction of woody biomass. Energy, 32, 196-202, 2007.

38. A.O. Ayeni F.K. Hymore, S.N. Mudliar, S.C. Deshmukh D.B. Satpute, J.A. Omoleye R.A. Pandey Hydrogen peroxide and lime based 
oxidative pretreatment of wood waste to enhance enzymatic hydrolysis for a biorefinery: Process parameters optimization using response surface methodology. Fuel 106, 187-194, 2013.

39. B.M. Jenkins, Baxter, L.L., Miles, T.R., Miles, Jr.T.R. Combustion properties of biomass. Fuel Processing Technology, 54:1746, 1998.

40. A. Demirbas, Relationships between lignin contents and fixed carbons of biomass samples. Energy Conversion and Management, 44:1481-1486, 2003.

41. P.K. Kanaujia, Sharma, Y.K., Garg, M.O., Tripathi, D., Singh, R. Review of analytical strategies in the production and upgrading of bio-oils derived from lingo-cellulosic biomass. Journal of Analytical and Applied Pyrolysis, 105:55-74, 2014.

42. K.. Jindo, H. Mizumoto, Sawada, Y., Sanchez-Monedero, M.A., Sonoki, T. Physical and chemical characterization of biochars derived from different agricultural residues. Biogeosciences, 11:6613-6621, 2014.

43. J. Heikkinen, J.C. Hordijk, de Jong, W., Spliethoff, H. Thermogravimetry as a tool to classify waste components to be used for energy generation. Journal of Analytical and Applied Pyrolysis, 71:883-900, 2004.

44. H.H. Acma, Mericboyu A.E., S. Kucukbayrak, Effect of mineral matter on the reactivity of lignite chars. Energy Conversion and Management, 42:11-20, 2001.

45. R.G. Fernandez, Garcia, C.P., Lavin, A.G., delas Heras, J.L.B. Study of main combustion characteristics for biomass fuels used in boilers. Fuel Processing Technology, 103:1626, 2012.

46. S. Darmawan, Wistara, N. J., Pari, G., Maddu, A., and Syafii, W. "Characterization of lignocellulosic biomass as raw material for the production of porous carbon-based materials," BioRes. 11(2), 3561-3574, 2016.

47. S.V. Vassilev, Baxter, D., Andersen, L.K., Vassileva, C.G. An overview of the chemical composition of biomass. Fuel, 89:913-933, 2010.

48. M.A. Sukiran, Kheang, L.S., Bakar, N.A., May, C.Y. Production and characterization of bio-char from the pyrolysis of empty fruit bunches. Am. J. Appl. Sci., 8: 984-988, 2011.

49. M. Keiluweit, Nico, P.S., Johnson, M.G., Kleber, M. Dynamic molecular structure of plant biomass-derived black carbon (Biochar). Environmental Science \& Technology, 44, 1247-1253, 2010.

50. Y.Y. Bi, Guan, J.P., Wang, D.L.. Comprehensive Utilization Technology of Straw Resources in China (in Chinese). Beijing: China Agricultural Science and Technology Press, 2008.
51. F. Ronsse, van Hecke, S., Dickinson, D., Prins, W. Production and characterization of slow pyrolysis biochar: influence of feedstock type and pyrolysis conditions, Global Change Biology Bioenergy, 5:104-115, 2013.

52. R. Zornoza, Moreno-Barriga, F., Acosta, J.A., Muñoz, M.A., Faz, A. 2016. Stability, nutrient availability and hydrophobicity of biochars derived from manure, crop residues, and municipal solid waste for their use as soil amendments. Chemosphere 144, 122-130.

53. T. Chen, Zhang, Y., Wang, H., Lu, W., Zhou, Z. Zhang, Y., Ren, L. Influence of pyrolysis temperature on characteristics and heavy metal adsorptive performance of biochar derived from municipal sewage sludge. Bioresour. Technol. 164, 47-54, 2014.

54. L. Gasparovic, Korenova, Z., Jelemensky, L. Kinetic study of wood chips decomposition by TGA. Chemical Papers, 64(2):174-181, 2010. DOI: $10.2478 / \mathrm{s} 11696-009-0109-4$.

55. H. Liang, Chen, L., Liu, G., H. Zheng, Surface morphology properties of biochars produced from different feedstocks. International Conference on Civil, Transportation and Environment, Published by Atlantis Press, 2016.

56. E. Biagini, Narducci, P., Tognoti, L. Size and structural characterization of lignin-cellulosic fuels after the rapid Devolatilization. Fuel, 87: 177-186, 2008.

57. S. Brodowski, Amelung, W., Haumaier, L., Abetz, C., Zech, W. 2005. Morphological and chemical properties of black carbon in physical soil fractions as revealed by scanning electron microscopy and energy-dispersive $\mathrm{x}$ ray spectroscopy. Geoderma, 128:116-129.

58. Y. Yao, B. Gao, M. Inyang, AR. Zimmerman, X. Cao, P. Pullammanappallil, et al., Biochar derived from anaerobically digested sugar beet tailings: characterization and phosphate removal potential. Bioresour Technol 102:6273-8, 2011. 